\title{
Extensive Calcinosis in an Adult Nigerian Woman with Dermatomyositis
}

\author{
Olufemi Adelowo ${ }^{a}$, Obiageli John-maduagwu'b ${ }^{\text {, Hamidu Ahmedc, Louis Olisakad }}{ }^{\text {d }}$ \\ aRheumatology Unit, Department of Internal Medicine, Lagos State University Teaching Hospital, Ikeja, Lagos, Nigeria

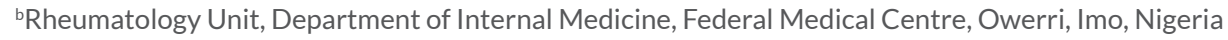 \\ 'Rheumatology Unit, Department of Internal Medicine, Aminu Kano Teaching Hospital, Kano, Nigeria \\ ${ }^{\mathrm{d}}$ Rheumatology Unit, Department of Internal Medicine, Federal Medical Centre, Abakaliki, Ebonyi, Nigeria
}

Received: 07/03/2015

Accepted: $30 / 03 / 2015$

Published: $20 / 04 / 2015$

How to cite this article: Adelowo O, John-Maduagwu O, Ahmed H, Olisaka L. Extensive calcinosis in an adult Nigerian woman with dermatomyosisis. EJCRIM 2015;2:doi: 10.12890/2015_000199

Conflicts of Interests: The authors declare that they have no conflicts of interest in this research

This article is licensed under a Commons Attribution Non-Commercial 4.0 License

\begin{abstract}
Objectives: Extensive calcinosis in a patient with dermatomyositis is a rare clinical presentation in adults. The aim of this report is to present the clinical and radiographic features of a 25 -year-old woman with dermatomyositis and extensive calcinosis.

Case Presentation: A 25-year-old woman with extensive calcinosis on background dermatomyositis is described.

Results: The clinical and radiographic features of the patient were consistent with dermatomyositis complicated by extensive calcinosis in an adult.

Conclusion: Dermatomyositis with extensive calcinosis is a rare clinical presentation in adults.
\end{abstract}

\section{LEARNING POINTS}

- Dermatomyositis (DM) is uncommonly reported in black Africans.

- Calcinosis, although frequently seen in children, is not common in adults with DM.

\section{KEYWORDS}

Rheumatology, calcinosis, dermatomyositis

\section{INTRODUCTION}

Dermatomyositis (DM) is a connective tissue disease presenting with multisystemic manifestations primarily affecting the musculoskeletal system, skin, heart, lungs and kidneys. It belongs to the group of idiopathic inflammatory myopathies (IIM). Diagnosis is based on the Bohan and Peter classification criteria ${ }^{[1]}$.

DM is mostly seen in children, with few reports of this condition among African children ${ }^{[2,3]}$ or adult black Africans ${ }^{[4]}$, but with some studies among adult African Americans ${ }^{[5,6,7]}$. Calcinosis while often reported in children ${ }^{[3]}$ is rarely associated with adult DM cases, which are mostly described in case reports ${ }^{[5,8,9,10]}$. A larger series was seen in a Brazilian study where calcinosis was seen in nine out of a cohort of $139 \mathrm{DM}$ patients $^{[11]}$. There are no documented reports of calcinosis in adult black African patients with DM. This report describes a Nigerian DM patient presenting with extensive dystrophic calcinosis.

\section{CASE SUMMARY}

A 25-year-old Nigerian woman, without previous features of DM, was diagnosed with DM at the age of 21 years at a rheumatology clinic in Lagos, Nigeria. She had presented then with rashes on the chest and arms. She also had marked difficulty in combing her hair and brushing her teeth, as well as ascending stairs and getting up from a sitting position. Physical examination showed erythematous rashes on the chest (Fig. 1) and arms (Fig. 2). She also had Gottron's lesions on the dorsum of the proximal interphalangeal joints (Fig. 3). Muscle power was grade 3 in the proximal muscles of the arms and leg with normal power in the distal muscles as well as a normal tendon reflex. Examination of other systems was essentially normal.

Laboratory investigations showed an erythrocyte sedimentation rate of $121 \mathrm{~mm} / \mathrm{hr}$, creatine kinase $337 \mathrm{U} / \mathrm{I}$ (15-170) and serum aldolase 9.5 IU/I (1.5-8.1); AST and ALT were within normal limits. Serology for ANA, ENA, dsDNA, Ro/SSA, La/SSB and anti-Jol were all normal. An electromyography (EMG) test, however, showed a myopathic pattern.

The patient was placed on a high dose of prednisolone (60 mg daily initially), azathioprine (150 mg daily) and methotrexate (15 mg weekly). Prednisolone has since been tapered off and methotrexate discontinued. She has also had physiotherapy. She has done well on these, with 


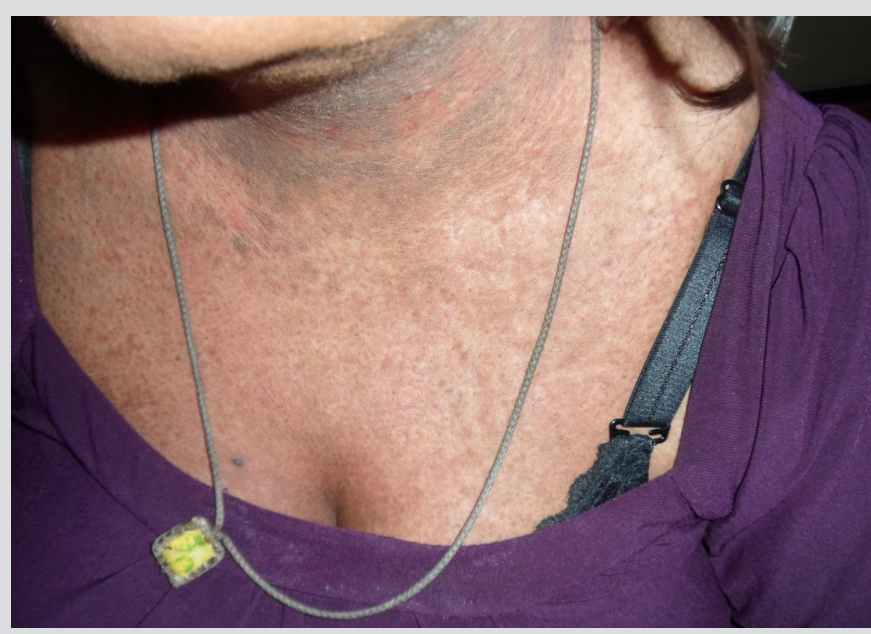

Figure 1: Erythematous rash on the patient's chest

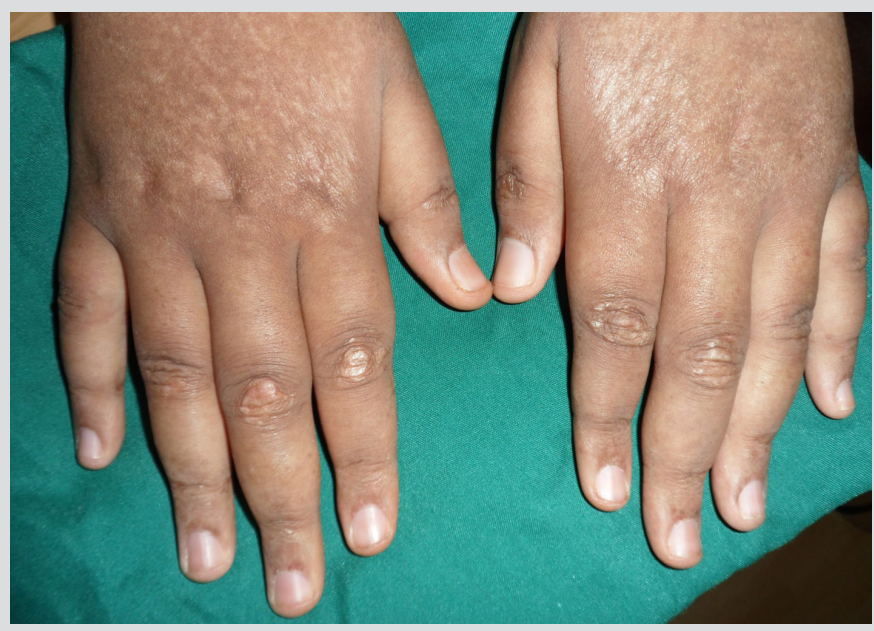

Figure 3: Gottron's lesions on the dorsum of the patient's proximal interphalangeal joints

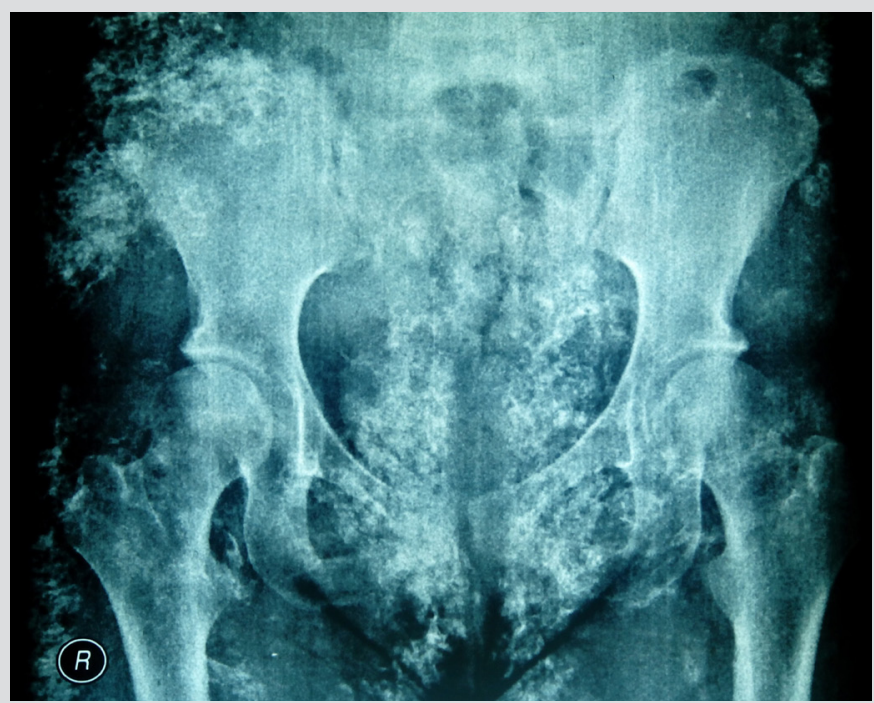

Figure 5: X-ray of the patient's pelvis

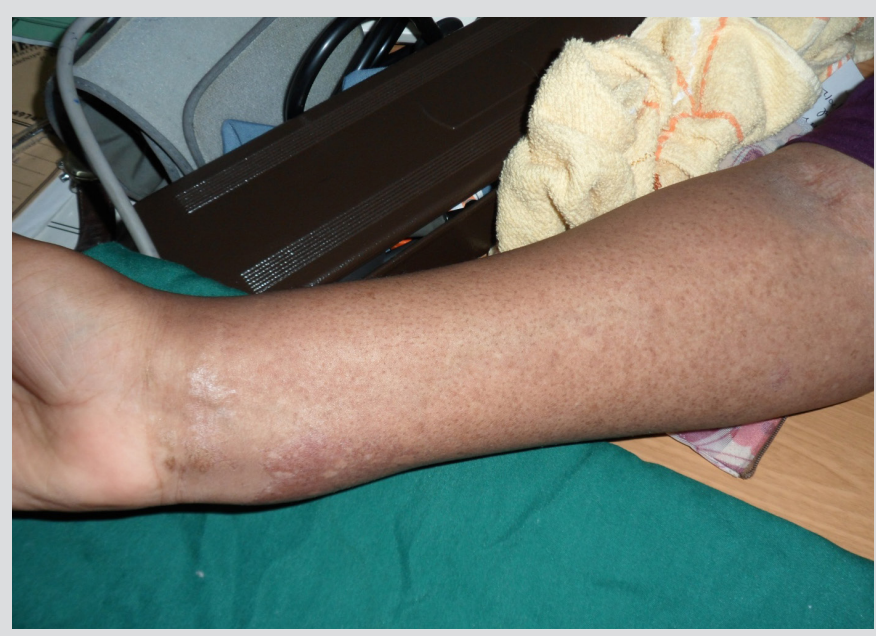

Figure 2: Erythematous rash on the patient's arms
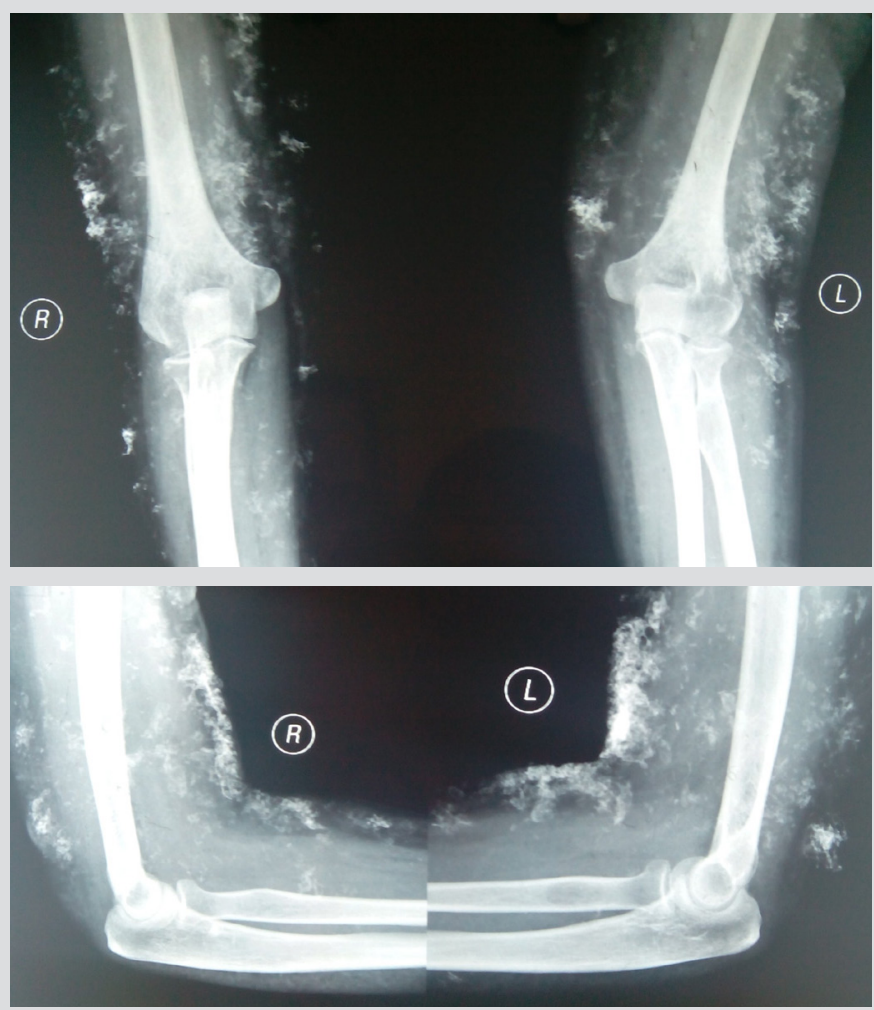

Figure 3 and $4: X$-rays of the patient's elbows

muscle power improving to grade 5 in the proximal muscles.

However, the patient presented 5 months ago with nodules around the elbow joints, increasing pain and reduced mobility in the elbow and hip joints. Radiographs of the elbows and pelvis showed extensive calcinosis (Figs. 4 and 5). Investigation showed serum calcium $2.36 \mathrm{mmol} / \mathrm{l}$ (2.15-2.65), phosphate $1.12 \mathrm{mmol} / \mathrm{I}(0.85-1.45)$ and lactic dehydrogenase $335 \mathrm{U} / \mathrm{I}(117-256)$. She has since been started on intravenous pamidronate (30 mg monthly) as well as a non-steroidal anti-inflammatory drug (NSAID). 


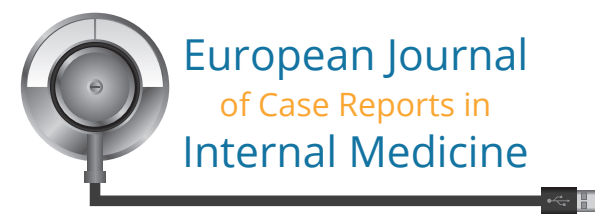

\section{DISCUSSION}

The patient had features of DM for 4 years before presenting with nodules and painful elbows and hips. Radiographs of the affected joints showed extensive dystrophic calcinosis in the elbows and pelvis. DM has rarely been reported in black Africans, possibly because of rarity or the few studies carried out. However, there are some reports of this disease among African Americans ${ }^{[5,6,7]}$.

Calcinosis is less frequently reported in adult DM than in childhood DM. For instance, none was seen among cases reported from Nigeria ${ }^{[4]}$, although single cases have been reported elsewhere ${ }^{[5,8,9,10]}$. The aetiopathogenesis and precipitating factors are poorly understood. It has been suggested that age-dependent factors could influence the risk of developing such ectopic calcifications ${ }^{[12]}$. Fisler et al. ${ }^{[13]}$ have studied 35 cases of juvenile DM and suggested that factors such as a delay in diagnosis, initiating treatment, prolonged disease duration and increased muscle enzymes may contribute to the development of calcinosis. Pachman et al. ${ }^{[14]}$ have also observed an association between calcinosis and a delay in DM diagnosis.

Different types of calcifications have been reported, such as calcinosis cutis and calcinosis universalis (dermal calcinosis or diffuse interstitial calcinosis) ${ }^{[15]}$. Dystrophic calcinosis, as seen in our patient, is the most frequently reported. In contrast to other types of calcinosis, it occurs in the presence of normal serum calcium and phosphate levels ${ }^{[16]}$, as in our reported case.

It has been estimated that calcinosis develops a mean of 3-4 years after the onset of DM ${ }^{[17]}$. Our patient had DM for about 4 years before the development of calcinosis.

Early aggressive treatment of DM remains the best strategy for the prevention of calcinosis. The treatment of established calcinosis is challenging as there is no consistent or standard therapy ${ }^{[18]}$. Different drugs have been used with variable outcomes. These include colchicine, probenecid, aluminium hydroxide, diltiazem, intravenous immunoglobulins, biphosphonates and even anti-TNFalpha.

Biphosphonate pamidronate has been used in our patient. This is in keeping with other reports where there appears to be complete remission of calcinosis ${ }^{[10,19,20]}$. The other advantage of intravenous pamidronate over oral biphosphonates is the avoidance of oesophagitis, thereby allowing greater compliance.

\section{REFERENCES}

1. Bohan A, Peter JB. Polymyositis and dermatomyositis. N Eng J Med 1975;292:344-347.

2. Adelowo O, Nwankwo M, Olaosebikan H. Juvenile dermatomyositis in a Nigerian girl. BMJ Case Reports 2014; doi: 10.1136/bcr-2013-202132.

2. Adelow O, Nwan W Tikly M. Juvenile dermatomyositis in South African children is characterised by frequent dystrophic calcifications: 2 cross sectional study. Paediatr Rheumatol 2014:12:2.

4. Adelowo OO, Edomwonyi U, Olaosebikan H. Inflammatory myopathies in Nigerians: case series and literature review. Afr J Med Medical Sci 2013:42:143-149.

5. Bahar D, Phillips TJ. Adult-onset dermatomyositis complicated by calcinosis cutis. Wounds 2004;16:364-370.

6. Majithia V, Harisdangkul V. Mycophenolate mofetil (Cellcept): an alternative therapy for autoimmune inflammatory myopathy. Rheumatology 2005;44:386-389.

7. Smoyer-Tomic KE, Amato AA, Fernandes AW. Incidence and prevalence of idiopathic inflammatory myopathies among commercially insured, Medicare supplemental insured, and Medicaid enrolled populations: an administrative claims analysis. BMC Musculoskelet Disord 2012;13:1-13.

8. Shah R, Ellis S. Subcutaneous fat calcinosis in adult onset dermatomyositis. BMJ Case Reports 2011; doi:10.1136/bcr.05.2011.4268

9. Presley BC, Bush JS, Watson SC. Dermatomyositis with extensive calcification in an adult. West J Emerg Med 2012;13:136-138.

10. Terroso G, Bernardes M, Aleixo A, Madureira P, Vieira R, Bernardo A, et al. Therapy of calcinosis universalis complicating adult dermatomyositis. Acta Reumatol Port 2013;8:44-48.

11. Souza FH, Barros TB, Levy-Neto M, Shinjo SK. Adult dermatomyositis: experience of a Brazilian tertiary care centre. Rev Bras Reumatol 2012;52: 892-902.

12. Callen JP. Dermatomyositis. Lancet 2000;355:53-57.

13. Fisler RE, Liang MG, Fuhlbrigge RC, Yalcindag A, Sundel RP. Aggressive management of juvenile dermatomyositis results in improved outcome and decreased incidence of calcinosis. J Am Acad Dermatol 2002:47:505-511.
2isler RE, Liang MG, Fuhlbrigge RC, Yalcindag A, Sundel RP. Aggressive management of juvenile dermatomyositis results in improved outcome and decreased incidence of

14. Pachman LM, Boskey AL. Clinical manifestation and pathogenesis of hydroxyapatite crystal deposition in juvenile dermatomyositis. Curr Rheumatol Rep 2006;8:236-243.

15. Santili C, Akkari M, Waisberg G, Kessler C, Alcantara T. Calcinosis universalis: a rare diagnosis. J Pediatr Orthop B 2005;14:294-298.

16. Chander S, Gordon P. Soft tissue and subcutaneous calcification in connective tissue diseases. Curr Opin Rheumatol 2012;24:158-164. doi: 10.1097/BOR.0b013e32834ff5cd

17. Abdallah-Lotf M, Grasland A, Vinceneux P, Sigal-Grinberg M. Regression of calcinosis cutis with diltiazem in adult dermatomyositis. Eur J Dermatol 2005;15:102-104.

18. Fleury J, Guillet G, Anyfantakis V, Huguier V. Unusual calcinosis of muscular legs in a 37 year old patient with a history of juvenile dermatomyositis. Eur J Dermatol 2010;20:647-648.

19. Slimani S, Abdessemed A, Haddouche A, Ladjouze-Rezig A. Complete resolution of universal calcinosis in a patient with juvenile dermatomyositis using pamidronate. Joint Bone Spine 2010;77:70-72.

20. Marco Puche A, Calvo Penades I, Lopez Montesinos B. Effectiveness of the treatment with intravenous pamidronate in calcinosis in juvenile dermatomyositis. Clin Exp Rheumatol 2010;28:135-140. 